Como citar: Marcon, S. R. A., \& Lucas, J. I. P. (2022). Modernização, riscos sociais e psicossociais. PSI UNISC, 6(1), 110-124. doi: 10.17058 psiunisc.v6i1.16460

\title{
Modernização, riscos sociais e psicossociais
}

\author{
Modernización, riesgos sociales y psicosociales
}

\author{
Modernization, social and psychosocial risks
}

\author{
Silvana Regina Ampessan Marcon \\ Universidade de Caxias do Sul (UCS), Caxias do Sul - RS/Brasil \\ ORCID: 0000-0002-7726-9900
}

E-mail: sramarco@gmail.com

João Ignacio Pires Lucas

Universidade de Caxias do Sul (UCS), Caxias do Sul - RS/Brasil

ORCID: 0000-0002-6307-1338

E-mail: jiplucas@ucs.br

\begin{abstract}
Resumo
O processo de modernização vivenciado, principalmente nas duas últimas décadas do século passado e nas décadas iniciais do século XXI, apresenta alguns riscos sociais e psicossociais que são fenôme-nos resultantes desse processo. Existem tentativas de minimizá-los de diferentes maneiras, mas nem todos os países conseguiram efetivamente minimizar os riscos pré-modernos, chamados de "visíveis" e os riscos "invisíveis" que estão muito atrelados ao desenvolvimento da tecnologia gerando desafios. Existem visões sobre os padrões culturais contemporâneos que apontam em sentidos diferentes: ou de valores de autoexpressão, ou de sentimento de luto. O objetivo do presente estudo é identificar se existem efeitos nos valores de autoexpressão e no sentimento de luto como desdobramentos culturais à modernização contemporânea, que não são opostos, mas complementares. Para tanto, foram realiza-das uma revisão teórica e uma testagem empírica sobre a relação entre os riscos sociais e psicossociais - a partir da obra de Beck (2010) - e o sentimento de luto - identificado na obra de Zizek (2010) -, e uma análise quantitativa a partir dos dados da sétima rodada (2017/2020) da Pesquisa Mundial de Valores, para a testagem empírica de valores de autoexpressão e sobrevivência identificados por In-glehart e Wezel (2009). A hipótese é que tais valores, de autoexpressão e sobrevivência, materializam culturalmente a dicotomia entre os riscos e o luto, especialmente num mundo em mudança e que há grande oscilação entre perspectivas otimistas e pessimistas sobre os efeitos da modernização. O mun-do vem passando por profundas mudanças tecnológicas, econômicas e sociais que podem ser medidas de forma quantitativa, em índices e indicadores de desenvolvimento humano e social, mas também de formação de valores. A modernização dos últimos séculos trouxe alento para vastas camadas da po-pulação, mas também trouxe desesperança e medo. O medo já foi relacionado aos valores de sobrevi-vência, mas ele também pode estar, como sentimento de luto, relacionado aos valores de autoexpres-são, numa espécie de cansaço que as pessoas estão tendo com esse apelo todo por felicidade, autoa-juda, segurança e conforto.
\end{abstract}

Palavras-chaves: Riscos sociais; Riscos psicossociais; Valores de autoexpressão; Luto.

\section{Resumen}

El proceso de modernización vivido, principalmente en las dos últimas décadas del siglo pasado y en las primeras décadas del siglo XXI, presenta algunos riesgos sociales y psicosociales que son fenóme-nos resultantes de este proceso. Hay intentos de minimizarlos de diferentes formas, pero no todos los países han logrado minimizar de manera efectiva los riesgos premodernos, denominados "visibles" y los riesgos "invisibles" que están íntimamente ligados al desarrollo de la tecnología generando desa-fíos. Hay puntos de vista sobre patrones culturales contemporáneos que apuntan en diferentes direc-ciones: ya sea valores de autoexpresión o sentimientos de duelo. El objetivo del presente estudio es identificar si existen efectos sobre los valores de la autoexpresión y el sentimiento de duelo como desarrollos culturales a la modernización contemporánea, que no son opuestos, sino complementarios. Para ello, se realizó una revisión teórica y una contrastación empírica sobre la relación entre los riesgos sociales y psicosociales basados en el trabajo de Beck (2010) - y el sentimiento de duelo -identificado en el trabajo de Zizek (2010) -, y un análisis cuantitativo basado en datos de la séptima ronda (2017/2020) de la Encuesta Mundial de Valores, para la prueba empírica de los valores de autoexpre-sión y supervivencia identificados por Inglehart y Wezel 
(2009). La hipótesis es que tales valores, de autoexpresión y supervivencia, materializan culturalmente la dicotomía entre riesgos y duelo, especialmente en un mundo cambiante y que existe una gran oscilación entre perspectivas optimistas y pe-simistas sobre los efectos de la modernización. El mundo ha venido atravesando profundos cambios tecnológicos, económicos y sociales que se pueden medir cuantitativamente, en índices e indicadores de desarrollo humano y social, pero también en la formación de valores. La modernización de los úl-timos siglos ha traído alivio a grandes sectores de la población, pero también ha traído desesperanza y miedo. Ya se ha relacionado el miedo con los valores de supervivencia, pero también puede serlo, como un sentimiento de duelo, relacionado con los valores de la autoexpresión, una especie de can-sancio que está teniendo la gente con todo este llamamiento a la felicidad, a la autoayuda, seguridad y comodidad.

Palabras clave: Riesgos sociales; Riesgos psicosociales; Valores de autoexpresión; Duelo.

\begin{abstract}
The modernization process experienced, mainly in the last two decades of the last century and in the initial decades of the 21 st century, presents some social and psychosocial risks that are phenomena resulting from this process. There are attempts to minimize them in different ways, but not all coun-tries have managed to effectively minimize the pre-modern risks, called "visible" and the "invisible" risks that are closely linked to the development of technology generating challenges. There are views on contemporary cultural patterns that point in
\end{abstract}

different directions: either of self-expression values, or of a feeling of mourning. The objective of the present study is to identify whether there are effects on the values of self-expression and the feeling of mourning as cultural developments to contempo-rary modernization, which are not opposites, but complementary. To this end, a theoretical review and empirical testing were carried out on the relationship between social and psychosocial risks - based on the work of Beck (2010) - and the feeling of mourning - identified in the work of Zizek (2010) -, and a quantitative analysis based on data from the seventh round (2017/2020) of the World Values Survey, for the empirical testing of self-expression and survival values identified by Inglehart and Wezel (2009). The hypothesis is that such values, of self-expression and survival, culturally mate-rialize the dichotomy between risks and grief, especially in a changing world and that there is great oscillation between optimistic and pessimistic perspectives on the effects of modernization. The world has been going through profound technological, economic and social changes that can be measured quantitatively, in indices and indicators of human and social development, but also in the formation of values. The modernization of the last few centuries has brought relief to vast sections of the population, but it has also brought hopelessness and fear. Fear has already been related to survival values, but it can also be, as a feeling of mourning, related to the values of self-expression, a kind of fatigue that people are having with all this appeal for happiness, self-help, security and comfort.

Keywords: Social risks; Psychosocial risks; SelfExpression Values; Grief.

\section{Introdução}

Novos riscos sociais e psicossociais intrometeram-se no processo de modernização dos últimos séculos (Beck, 2010). Seja pelo lado econômico, materializado pelas diferentes fases da industrialização, seja pelo lado social da urbanização, ou até mesmo pelo político e jurídico do desenvolvimento do Estado Democrático de Bem-Estar Social, existe a tentativa de minimização de riscos derivada de todos esses esforços e movimentos. Pelo menos, três tipos de riscos pré-modernos foram intensamente atacados pela modernização em curso na esmagadora maioria dos países: os riscos materiais caracterizados pela fome, miséria, pobreza; os riscos da ignorância caracterizados pelo analfabetismo e desinformação, bem como pela precariedade tecnológica e científica; e os riscos da falta de direitos, especialmente os políticos quando da existência de ditaduras e de autoritarismos. Entretanto, dois resultados podem ser verificados já no século XXI: nem todos os países conseguiram efetivamente minimizar os riscos pré-modernos, que também podem ser chamados de "visíveis" (Beck, 2010, p. 24), além de que "novos" riscos foram surgindo justamente a partir dos esforços das áreas mais desenvolvidas da tecnologia, criando-se os chamados "riscos invisíveis" (Beck, 2010, p. 25). Nesse sentido, os riscos sociais e psicossociais da contemporaneidade estão trazendo desafios à modernização. A noção de risco é utilizada nas diferentes partes do mundo. O repertório de cada pessoa irá contribuir para que perceba ou não determinada situação como um perigo, ou uma ameaça a si (Spink, 2001), considerada risco. Estes riscos 
acompanham as pessoas, quer na sua vida pessoal, quer na vida profissional. $\mathrm{Na}$ vida profissional, por exemplo, as variáveis que contribuem para aumentar ou diminuir a percepção de riscos podem estar relacionadas às transformações tecnológicas, que de certa maneira, induzem os trabalhadores à sua adaptação nas diferentes organizações, e podem estar relacionados ao estilo de gestão.

A modernização dos últimos séculos parece produzir mudanças culturais significativas, como afirmam Inglehart e Welzel (2009). Para esses autores, a variação transcultural tem características psicológicas importantes, tal como na tensão alternada entre tendências de coletivismo versus individualismo, bem como no aumento crescente da valorização da autonomia. Por isso, esses próprios autores defendem a ideia de que nessa troca de valores há uma passagem lenta, mas permanente, entre valores materiais de sobrevivência, como na defesa do emprego e segurança, para outros valores caracterizados pela defesa da autoexpressão individual. Nesse sentido, o individualismo e a autonomia estariam enfatizando nas últimas décadas uma maior valorização da possibilidade da escolha humana nos processos de tomada de decisão individuais e coletivos.

Porém, de outro lado, Zizek (2010) também apresenta desdobramentos na "consciência social" derivados das profundas alterações sociais contemporâneas, mas como efeitos de criação de uma "cultura de luto". Ou seja, as duas visões sobre os padrões culturais contemporâneos apontam em sentidos diferentes: ou de valores de autoexpressão ou de sentimento de luto. Por isso, a hipótese central presente neste texto é que tais efeitos, de autoexpressão e luto, são desdobramentos culturais complementares à modernização contemporânea, por mais contraditórios que possam parecer.

Para tanto, são realizadas duas ações teóricas e práticas. De um lado, são revisados os conceitos de riscos sociais e psicossociais, baseados na obra de Beck (2010), a partir da análise do sentimento de luto (como consciência social atual) trazida por Zizek (2010). De outro lado, essas duas dimensões, autoexpressão e luto, são testadas empiricamente para a verificação se elas contribuem com a capacidade explicativa dos padrões culturais contemporâneos. O teste empírico é realizado com os dados da sétima rodada da Pesquisa Mundial de Valores (Inglehart et al., 2020), maior pesquisa de opinião do mundo, com uma amostra de mais de 120 mil entrevistados de setenta e sete países de todos os continentes. Os valores de autoexpressão são marcados por uma variável em forma de índice (com resultados entre zero e 1), quanto mais perto de 1 , mais forte é o apoio aos valores de autoexpressão, enquanto que mais perto de zero, mais forte é a defesa dos valores de sobrevivência (valores mais próximos dos medos e inseguranças do luto). Os medos e inseguranças são testados a partir de duas variáveis ordinais do tipo likert, na medida em que oscilam quanto à concordância ou discordância entre os entrevistados com a força desses sentimentos. Para verificação complementar sobre a relação entre os valores de autoexpressão e sobrevivência com a dimensão socioeconômica, também é analisado o cruzamento das variáveis culturais (autoexpressão e sobrevivência com o Índice de Desenvolvimento Humano, proposto pelo Programa das Nações Unidas Para o Desenvolvimento (PNUD), já amplamente conhecido. Os testes são baseados em duas técnicas estatísticas: do gráfico de dispersão a partir dos resultados médios dos setenta e sete países pesquisados na sétima rodada da Pesquisa Mundial de Valores; e com a regressão linear $\left(\mathrm{R}^{2}\right)$ entre as variáveis em questão. Para tanto, é utilizado o software estatístico SPSS, versão 26.0.

\section{Vivendo no meio dos tempos}

O maior risco psicossocial da época contemporânea é o sentimento de luto como reação da consciência social em relação às profundas transformações (e crises) oriundas de quatro grandes causas (Zizek, 2010): a crise ecológica, a crise biogenética, a crise tecnológica e de gestão e, por fim, da crise de 
novas formas de exclusão social. O luto, segundo Freud (1917/2010) é uma vivência normal diante da perda de algo e tem como características a tristeza e o desânimo entre outras. O desânimo provoca a perda do interesse pelo mundo externo e a inibição da atividade em geral. O risco psicossocial está também na maneira como a sociedade reconhece e dá sentido a esses problemas: como "forma de luto". Para tanto, Zizek (2010) utiliza-se do modelo proposto pela psicóloga Kübler-Ross (2009) em termos das "fases do luto" (cinco ao todo).

Podemos distinguir as mesmas cinco figuras no modo como nossa consciência social tenta lidar com o apocalipse anunciado. A primeira reacção é a da denegação ideológica: não há qualquer alternação fundamental; a segunda é ilustrada pelas explosões de cólera perante as injustiças da nova ordem mundial; a terceira compreende as tentativas de negociação ("Se mudarmos as coisas sob este e aquele aspecto, talvez a vida possa continuar como antes"); quando as negociação se gora, instalam-se a depressão e o isolamento solitário; por fim, depois de atravessar este pontozero, o sujeito deixa de perceber a situação como uma ameaça, vendo antes nela a ocasião de um novo começo..."[Destaques do autor]. (Zizek, 2010, p. 15).

Por isso, Zizek (2019) aponta que é mais fácil pensar no fim do mundo do que no fim do capitalismo. Diferentemente como a hegemonia dominante no neoliberalismo global (Han, 2019), Zizek (2015) já trouxe à tona as questões problemáticas da época atual, os chamados "problemas no paraíso". E o sentimento de luto articula as duas grandes possibilidades de desfecho nesse contexto: ou a humanidade perece, presa a um sentimento de luto sem fim, ou o luto, pelas características da última fase, encontra solução transformadora. Mas, também o cansaço pode predominar (Han, 2015), até, muitas vezes, como efeito do discurso motivacional que impera na tentativa de "negociação" com as diferentes crises.

$\mathrm{O}$ excesso de positividade se manifesta também como excesso de estímulos, informações e impulsos. Modifica radicalmente a estrutura e economia da atenção. Com isso se fragmenta e destrói a atenção. Também a crescente sobrecarga de trabalho torna necessária uma técnica específica relacionada ao tempo e à atenção, que tem efeitos novamente na estrutura da atenção. A técnica temporal e de atenção multitasking (multitarefa) não representa nenhum progresso civilizatório. A multitarefa não é uma capacidade para a qual só seria capaz o homem na sociedade trabalhista e de informação pósmoderna. Trata-se antes de um retrocesso. (Han, 2015, p. 20).

O mais interessante, é que se forem seguidos os passos de Harari (2015), a nova agenda da humanidade, para a fase do "Homo Deus", seria baseada na busca pela felicidade, junto com a imortalidade. Porém, ao contrário do esperado, a felicidade tem sido substituída pelo luto. Se a modernização empreendida no século XX começou sob a égide do mal-estar na civilização (Freud, 2010), a civilização hiper consumista do século XXI (Lipovetsky \& Serroy, 2011) transformou-se na busca incessante pelo prazer e gozo. Mas, o prazer tem sido substituído pelo sofrimento, medo, angústia e luto. Se não substituído, o prazer tem sido preenchido pelos riscos.

Na modernidade tardia, a produção social de riqueza é acompanhada sistematicamente pela produção social de riscos. Consequentemente, aos problemas e conflitos distributivos da sociedade da escassez sobrepõem-se os problemas e conflitos surgidos a partir da produção, definição e distribuição de riscos científicotecnologicamente produzidos. (Beck, 2010, p. 23). 
Há um ponto em comum em todos esses contextos de crise, a tecnologia. Se os problemas anteriores eram baseados na fome, hoje também temos a questão dos distúrbios alimentares, e de todas as toxinas que as pessoas estão ingerindo através dos alimentos. Por isso, a radioatividade, os elementos químicos dos alimentos, as matérias-primas sintéticas derivadas do petróleo, além das emissões de $\mathrm{CO} 2$ em ritmo crescente aumentam os chamados "riscos invisíveis". Riscos esses que se espalham também pelas redes sociais e internet, bem como sobre as relações sociais no mundo do trabalho (como os assédios morais e sexuais).

Se a tecnologia também pode servir ao aumento dos riscos, e não apenas a desejada minimização, uma das grandes questões sociais do momento é a verificação de como a sociedade reconhece e interpreta o papel da tecnologia e dos "novos riscos". Considerando a tecnologia como um dos aspectos relacionados ao contexto de crise e que por sua vez, pode ser considerada um dos fatores de risco, é necessário também entender como ele (risco) está presente nas organizações que dependem, de certa maneira, da tecnologia para sobreviverem. O conceito de transformação digital, por exemplo, surge a partir do desenvolvimento das tecnologias e da evolução de seu uso. Este conceito é caracterizado como o processo de integrar tecnologia digital para utilização em qualquer âmbito da vida (Malvezzi, 2013; Yoo, Boland, Lyytinen, \& Majchrzak, 2012; Vial, 2019). A transformação digital está impactando de diferentes formas nas organizações, tanto para melhorias nos processos de trabalho como também um risco psicossocial, uma vez que muitos trabalhadores estão sentindo-se "pressionados" pela necessidade de acompanhar essa evolução, nem sempre desejada, e que provoca sentimentos de insegurança, principalmente quanto a perder o emprego, evidenciando a presença de risco invisível.

Nesse sentido, a obra de Zizek (2010) sobre o sentimento de luto presente na consciência social como resposta aos problemas globais, atende, em parte, o importante desafio social de superação dos riscos sociais e psicossociais contemporâneos. Mas, de outro lado, também têm surgido novos padrões culturais, como o dos valores de autoexpressão (Inglehart \& Welzel, 2009).

Será que os medos relacionados à consciência social de luto, tem relação com o surgimento e desenvolvimento de valores de autoexpressão?

Os valores de autoexpressão, segundo Inglehart e Welzel (2009), compõem temas impactados pelo desenvolvimento humano e pós-industrialização. São compostos por três grandes conjuntos de valores: de autonomia e autoafirmação individual e coletiva; de tolerâncias sociais em geral, como a da igualdade de gênero; e um profundo sentido de engajamento político para a decisão de questões importantes da esfera pública. Tais valores estariam num polo oposto a valores de sobrevivência, esses mais pertinentes a sociedades de escassez. Por isso, se para Beck (2010), no final do século XX havia a contradição entre os padrões de riscos relacionados à sociedade de escassez, de um lado, e os riscos da modernidade reflexiva, ou tardia, de outro lado, há uma profunda semelhança entre essa noção e a dos polos opostos entre os valores de autoexpressão (pertinentes à modernidade reflexiva) e os valores de sobrevivência (da sociedade da escassez).

Como tem sido revelado nos relatórios das (sete) rodadas da pesquisa mundial de valores (Inglehart et al., 2020), desde os anos 80 do século $\mathrm{XX}$, a maioria da população mundial ainda tem valores de sobrevivência em maior quantidade do que valores de autoexpressão. Os valores de sobrevivência são voltados para a priorização de questões materiais como emprego e renda, bem como há uma grande preocupação com questões derivadas do sentimento de insegurança pública (com medo da violência). Já os valores de autoexpressão são típicos de sociedades mais desenvolvidas. Por isso, se a humanidade está desejosa de mais felicidade, tal sentimento combina melhor com o desenvolvimento 
humano e com valores de autoexpressão, enquanto os sentimentos de sobrevivência de sociedades de escassez até podem desejar felicidade, mas de um patamar diferente, o que pode combinar muito bem com o sentimento de luto, até pelo reconhecimento de que a tal felicidade demandaria um esforço irreal para populações dos países não desenvolvidos. Segundo Diener, Oishi, e Lucas (2002), felicidade é um bem-estar-subjetivo que corresponde à avaliação, tanto cognitiva quanto afetiva que uma pessoa faz referente a sua própria vida. A autonomia, considerada um valor de auto expressão, quando existente na vida profissional dos trabalhadores, contribui para sentirem-se mais satisfeitos com a função que exercem, e consequentemente, tem influência na qualidade de vida no trabalho e felicidade. Bendassolli e Borges-Andrade (2011) compreendem a autonomia como a possibilidade de o indivíduo assumir responsabilidades, de exercer seu julgamento para resolver problemas e de tomar decisões com liberdade. O termo é definido como a possibilidade do indivíduo regular as suas tarefas conforme as suas necessidades e o seu ritmo. Van Horn, Taris, Schaufeli e Scheurs (2004) definem a autonomia como à liberdade do trabalhador para tomar suas próprias decisões no trabalho. É importante explicitar que a pesquisa mundial de valores é uma investigação sobre valores socioculturais e políticos, desenvolvida em cerca de 100 sociedades em todos os continentes habitados, abrangendo cerca de 80 por cento da população do planeta.

A cultura e os valores influenciam múltiplas dimensões que estão relacionadas ao bem-estar e as possibilidades de mal-estar. Uma dessas áreas correlacionadas à cultura é a área da saúde. Roudijk, Donders e Stalmeier (2019) e Holum (2018) afirmam que os valores integrantes das culturas nacionais (como valores de autoexpressão ou de sobrevivência) impactam tanto saúde das pessoas quanto na dinâmica de funcionamento dos serviços de saúde. Já Rudnev e Savelkaeva (2018) destacam como os valores de autoexpressão estão na base de um maior apoio para a eutanásia, e de como tal apoio está relacionado à valorização da autonomia. E os transtornos mentais, uma meta-análise sobre a relação das pesquisas e a dimensão da cultura, pois os valores de autoexpressão podem também minimizarem pressões culturais autoritárias sobre os indivíduos (Kapitány-Fövény, et al 2018).

Também há uma relação especial da cultura de autoexpressão com a religiosidade. Zhuravlev (2017), bem como também Schihalejev, Kuusisto e Kallioniemi (2019) apontam as relações entre as narrativas religiosas e os valores culturais, como os de sobrevivência e autoexpressão, especialmente no tocante a temas sexuais, comportamentais e de identidade. E não apenas da religiosidade em si, mas da relação dela com culturas autoritárias, como no caso da Arábia Saudita (Ciftci, 2018; Teti, Abbott \& Cavatorta, 2019). Porém, mesmo na Europa, a religiosidade também pode estar atrelada às questões de riscos, especialmente nas disputas entre as diferentes facções culturais e religiosas (Noll, Rohmann, \& Saraglou, 2018), ou na formação das crianças para uma visão mais centrada na autonomia (Lövgren, 2018).

Outro aspecto cultural evidente referese as questões de migração e imigração, sempre um tema sensível aos riscos sociais e psicossociais. Nesse sentido, Cheung (2019) aponta como a segunda geração de imigrantes nos EUA, que tentam acompanhar as mudanças culturais de autoexpressão naquele país, especialmente para o mundo do trabalho, ou seja, pela ótica dos imigrantes trabalhadores e os ganhos que a autonomia da autoexpressão possa trazer.

$\mathrm{Na}$ modernidade, é possível então afirmar, que a autonomia tem um valor considerável para muitos trabalhadores, em diferentes etapas da vida, e quando não valorizado pode se transformar em risco para alguns, como apontam Krys, Uchida, Oishi e Diener (2018) sobre o papel do individualismo na cultura da contemporaneidade. Mas, ainda persistem problemas para as trabalhadoras mulheres aproveitarem plenamente os ganhos 
culturais de autoexpressão, como apontam Zafar (2019), no Paquistão.

\section{Riscos sociais e psicossociais e valores}

A modernidade é, também, consequência da evolução do conhecimento produzido sobre o ambiente e o homem, e isso contribui para gerar oportunidades, mas ao mesmo tempo, pode gerar riscos também (Giddens, 1994). Os riscos quando apresentam consequências drásticas são percebidos como mais ameaçadores e quando as pessoas acreditam ter familiaridade com a situação que apresenta o risco, é provável que percebam o risco moderadamente (Slovic, 1987). Assim, é possível afirmar que o contexto no qual as pessoas vivem vai interferir na percepção de risco, pois esta sofre influências externas. E, um aspecto que precisa ser considerado na modernidade, é a autoexpressão (considerado um valor) dos indivíduos, juntamente com a liberdade de expressão, que contribui para a autoafirmação e a visibilidade dos diferentes modos de vida nessa sociedade moderna (Rawls, 2011) e de enfrentamento aos possíveis riscos.

Os valores de autoexpressão são medidos por um conjunto de variáveis observáveis composta no instrumento da Pesquisa Mundial de Valores (Inglehart et al., 2020). Inglehart e Welzel (2009) afirmam que as prioridades de valores das pessoas estão mudando de materialistas, onde é enfatizada a segurança econômica e física, para metas que valorizam a autoexpressão e a qualidade de vida, principalmente na era pós-industrial. Já os valores de sobrevivência, ao contrário, enfatizam elementos culturais machistas e preconceituosos, bem como na extrema valorização da ordem e da religião. Por isso, os valores de sobrevivência formam um polo na escala de valores, enquanto que os valores de autoexpressão estão no polo oposto. Como indicadores desse índice escalar, encontram-se posicionamentos das pessoas em termos, como demonstram Inglehart e Welzel (2009): qualidade da liderança política entre homens e mulheres, satisfação com a situação financeira, filhos para a realização subjetiva da mãe, dificuldade na aceitação de estrangeiros, dificuldade de entendimento e de prática no sentido de ações que possam proteger o ambiente (como no devido recolhimento seletivo de resíduos sólidos), empregos e relações de trabalho mais vantajosas para os homens em detrimento das mulheres, entre outros elementos. Nesse sentido, uma forma de serem medidos tais sentimentos é escaloná-los num gradiente entre zero (extrema valorização da sobrevivência) e 1 (extrema valorização da autoexpressão).

No caso do Índice de Desenvolvimento Humano - IDH -, de forma diferente, ele é composto por três grandes dimensões de indicadores objetivos: saúde, renda e escolaridade. Também flutua entre zero (sem desenvolvimento) e 1 (desenvolvimento elevado).

O Gráfico 1 revela que há forte associação entre esses dois valores, no sentido de que as sociedades com maiores índices de autoexpressão são também as sociedades com maior IDH. O valor da regressão é $\mathrm{R}^{2}$ é de 0,681 $(\mathrm{p}<0,05)$, valor bem expressivo. No Gráfico 1 , a variável índice que agrega os valores de sobrevivência e de autoexpressão está no eixo y (vertical). Os países mais próximos da parte de baixo do eixo, como o Paquistão, Egito, entre outros, são os países nas quais a média da variável índice dos valores está muito baixa, ou seja, tais países têm populações mais apoiadoras dos valores de sobrevivência do que dos valores de autoexpressão. Por isso, ao contrário, os países na parte de cima do eixo, Islândia, Dinamarca e Noruega são aqueles nos quais a média da visão da população é de apoio aos valores de autoexpressão. No eixo $x$ (horizontal), o mesmo ocorre com a variável do Índice de Desenvolvimento Humano (IDH), sendo que os países posicionados do lado esquerdo, mais perto da base do eixo, são os países com menores IDH, como a Etiópia e a Nigéria. Da mesma forma, os países posicionados do lado direito, na parte superior do eixo, são os países com maior IDH, como Suíça e Noruega. O sentido da reta dos setenta e sete países dá um sinal da força de associação entre IDH e valores, especialmente na relação 
positiva entre maior IDH e defesa de valores de autoexpressão.

Os mesmos resultados positivos de regressão são verificados nos cruzamentos entre o índice de sobrevivência/autoexpressão e uma variável relacionada ao medo de perder o emprego. No Gráfico 2, por exemplo, os valores de sobrevivência/autoexpressão também estão associados positivamente com o medo de perder o emprego, ou de não conseguir achar uma atividade remunerativa. A regressão é positiva $\mathrm{r}=0,298(\mathrm{p}<0,05)$, ou seja, menor do que a regressão anterior, considerada relativamente forte, o que revela uma associação entre o medo de perder o emprego e os valores de sobrevivência, e, de outro lado, o não medo de perder o emprego e o maior percentual médio nos valores de autoexpressão. As sociedades com maiores resultados de medo são justamente as sociedades que se mantêm presas aos valores de sobrevivência, como o Paquistão e o Zimbábue. pois que tais valores acabam combinando-se de forma mais frequente com a infelicidade.

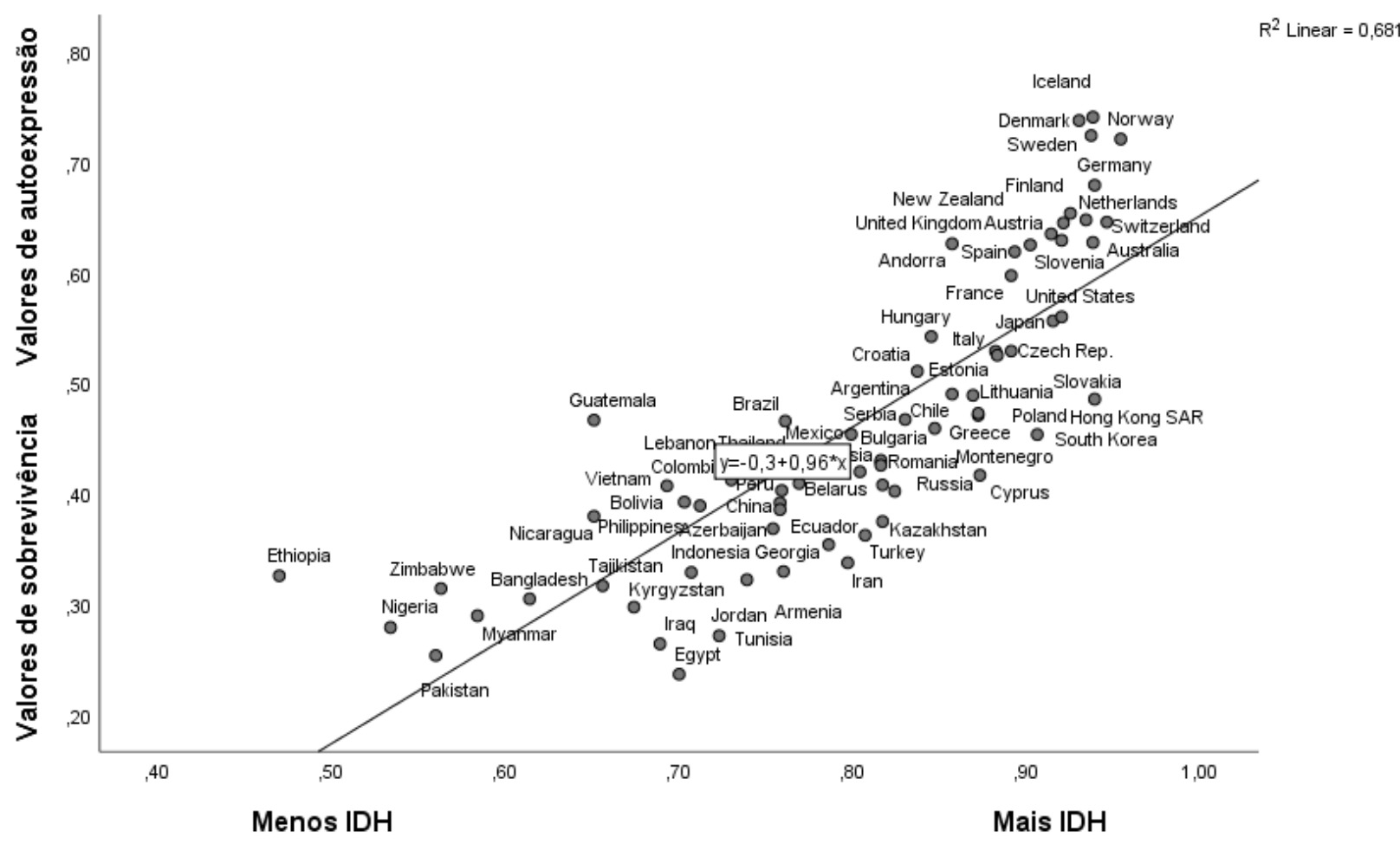

Gráfico 1. Valores de sobrevivência/autoexpressão e IDH, 2020.

Fonte: Pesquisa Mundial de Valores, Inglehart et al. (2020).

Dejours (2006), afirmou que as condições dos trabalhadores na França deste século são muito diferentes do que eram durante toda a segunda metade do século XX. Naquela época, quando os trabalhadores queriam mudar de emprego, tinham mais facilidade de encontrar um novo local de trabalho, havia pouco ou quase nada de desemprego. No início do século XXI, na França, existe uma nova pobreza e há muitas pessoas que vivem em situação de miséria. Os trabalhadores têm medo de perder seu emprego, pois isto pode ser um risco de se encontrar numa condição de miséria. Para Dejours (2006), é possível verificar que o medo das pessoas em perder o emprego está presente nos contextos de trabalho, implicando riscos para a integridade física, como por exemplo, sofrer acidentes no trabalho e doenças profissionais nas organizações de produção de bens. Também aqueles profissionais das organizações de serviços sofrem medos e 
riscos, pois, muitas vezes, são vítimas da violência dos clientes, dos usuários, no próprio exercício de suas atividades profissionais. Independente do local onde estão trabalhando, é possível verificar que o medo de perder o emprego é real, e para Meireles (2012), este medo é socialmente compartilhado pelos trabalhadores. Cada trabalhador sente de sua maneira e este sentimento pode estar atrelado ao que observam no seu cotidiano quanto a situação geradora de medo. Para a autora, o medo de perder o emprego está relacionado à percepção do risco sobre o que poderá acontecer.

Além desses riscos, que estão atrelados às sociedades presas aos valores de sobrevivência, precisamos atentar para aqueles considerados invisíveis. Salvagni e Veronese (2017) afirmam que a origem da terminologia risco invisível, aqueles relacionados aos fatores psicossociais, surgiu de estudo com trabalhadores do setor elétrico, pois na percepção deles, a eletricidade não pode ser vista e mesmo assim oferece determinados riscos. Esses riscos invisíveis produzem ansiedade, sofrimento, insegurança, pois são difíceis de serem reconhecidos e controlados, tanto pelo trabalhador como pela organização da qual fazem parte.

Pires, Pinto e Justo (2021) realizaram uma pesquisa para compreender de que maneira as pessoas que vivem no estado do Espírito Santo (BR) se relacionam com a violência urbana, e como percebem o risco referente a violência. Os resultados permitiram aos pesquisadores afirmarem que o risco que mais preocupa os participantes é o risco de ser assaltado na rua. Outra descoberta foi a de que os participantes tendem a se preocupar mais com a violência quando alguém relata uma violência sofrida ou quando ocorrem episódios de violência aonde moram, do que quando tomam conhecimento de um acontecimento violento pela mídia. A violência é um risco social que pode resultar em riscos psicossociais, pois provocam sentimentos de medo, insegurança e impunidade quando relacionada as práticas de violência.

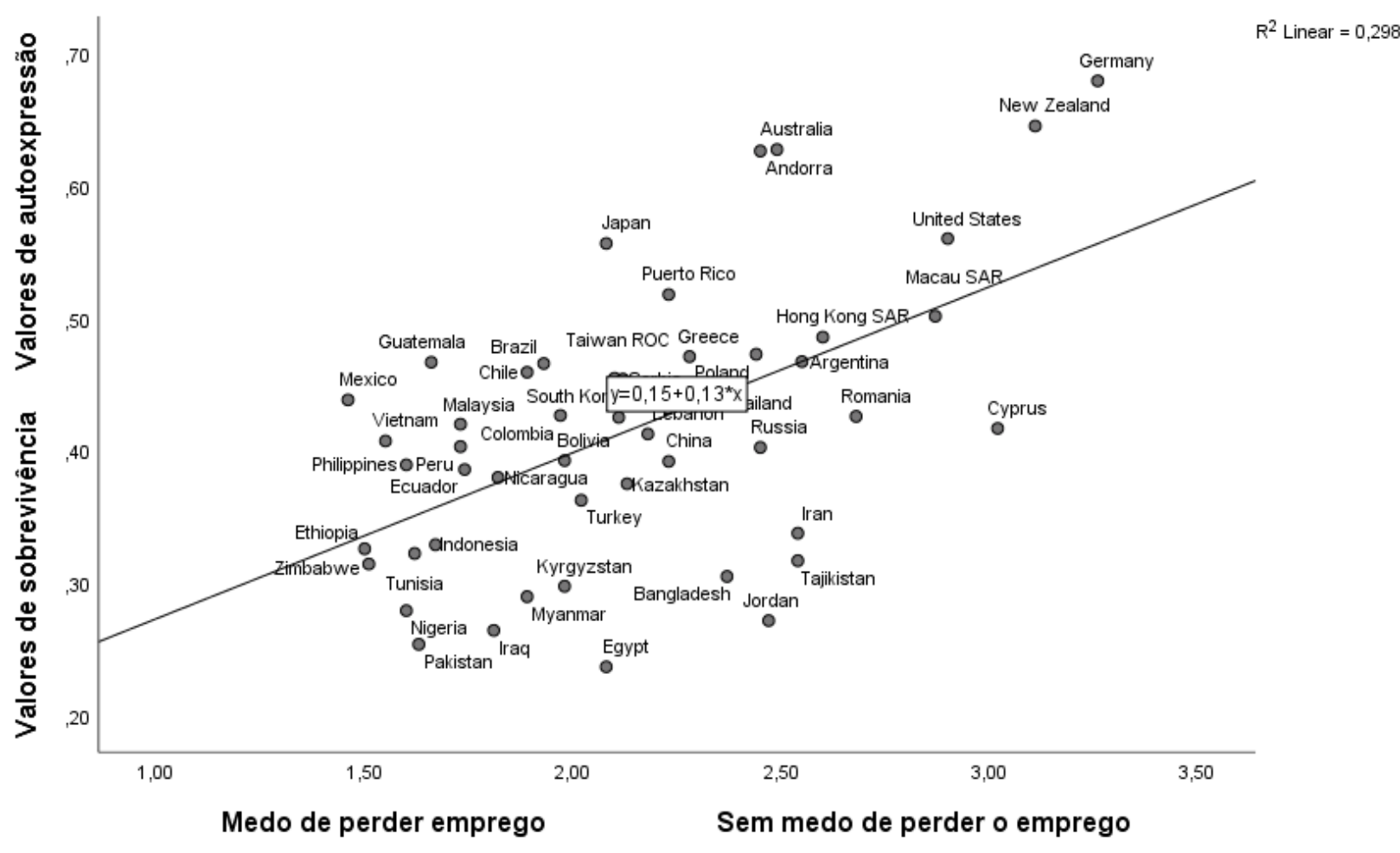

Gráfico 2. Valores de autoexpressão/sobrevivência e medo de perder o emprego, 2020. Fonte: Pesquisa Mundial de Valores, Inglehart et al. (2020). 
Inseguranças no emprego, na vida pública e em casa estão relacionadas. Para Lourenço (2019) a dinâmica das sociedades, assim como da vida individual de cada um, indica a exposição com algum nível de risco. Por exemplo, a instabilidade, a imprevisibilidade e incerteza do mundo em que vivemos coloca em evidência a problemática da segurança como central em termos de temas de debate nas sociedades atuais. Essa centralidade está diretamente relacionada à sensação de vulnerabilidade das pessoas a um conjunto de novos riscos e ameaças que fortalecem o sentimento de insegurança, o que abrange várias dimensões da vida social, muito além da prevenção e combate da criminalidade e da manutenção à ordem pública ou ainda da defesa nacional. Também com correlação positiva, o
Gráfico 3 revela que os medos e riscos somamse nas sociedades menos desenvolvidas.

Os resultados mostram que há realmente um tipo de "luto social" na base cultural por causa de riscos visíveis (menos desenvolvimento) e invisíveis (ricos subjetivos baseados em medos de perda do emprego, segurança, entre outros). Ou seja, os riscos visíveis derivados da falta de desenvolvimento também são base para o surgimento de mais riscos, especialmente de riscos subjetivos (culturais). E a existência de riscos "invisíveis" também é reforçada pelas novas tecnologias energéticas, das matérias-primas sintéticas e elementos químicos dos alimentos, sempre com legislações menos rigorosas nos países em desenvolvimento (ou com pobreza e fome).

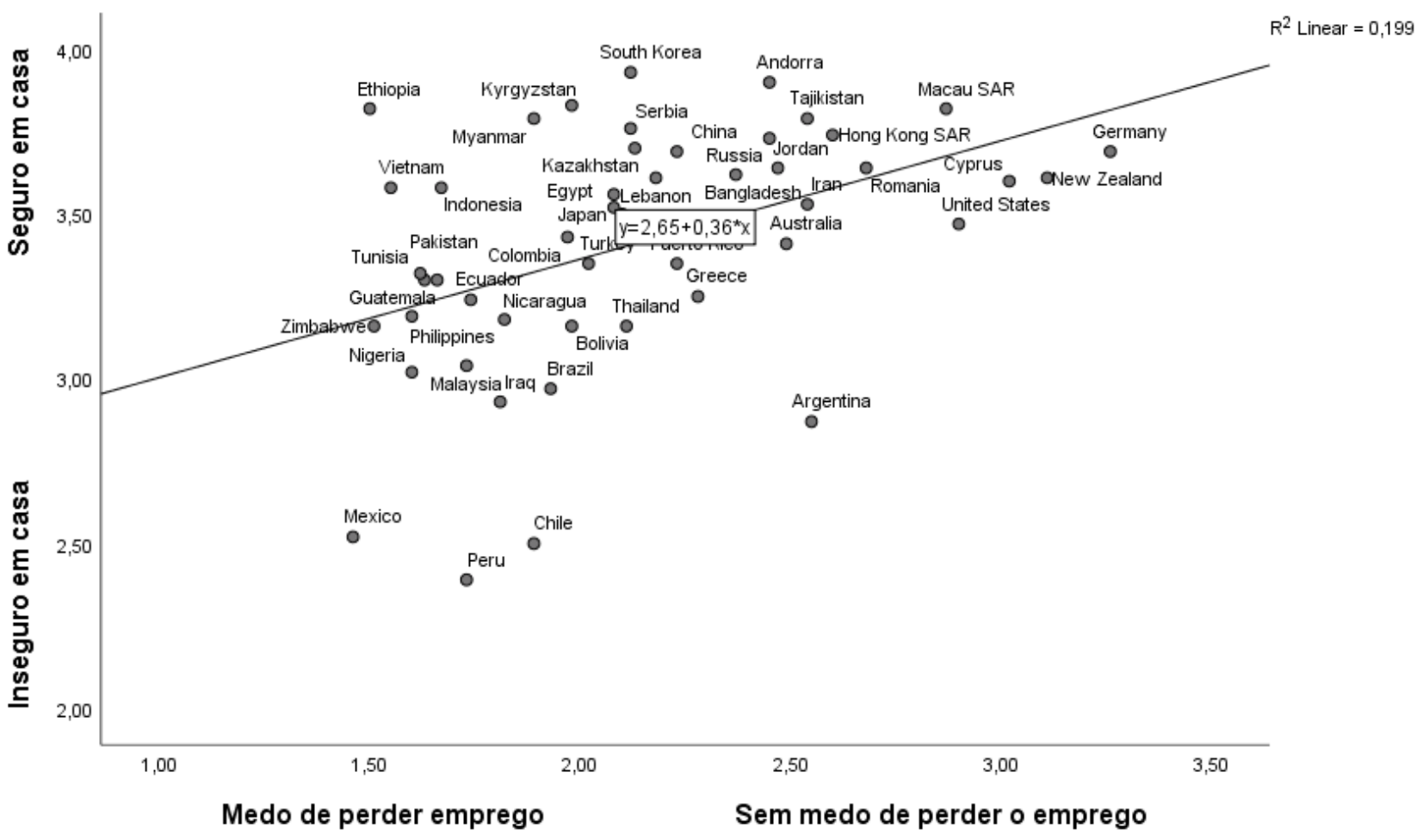

Gráfico 3. Sentimento de insegurança e medo de perder o emprego, 2020.

Fonte: Pesquisa Mundial de Valores, Inglehart et al. (2020).

O Gráfico 3 revela de forma mais tênue tal associação, entre o medo de perder o emprego e a insegurança em casa. Como pode ser visto, a maior parte dos países têm médias da variável de insegurança de forma a marcar mais a "segurança. A maior parte dos setenta e sete países está na parte superior do eixo y (vertical), que é o sinal de uma média maior da segurança para a variável indicada. Mas, como já havia sido visto, em relação ao medo de perder o emprego, a dispersão é maior, pois grande parte dos países têm populações com medo de perder o emprego. 
Para Lourenço (2019) à noção de risco não pode ser separada da ideia de incerteza e esta se associa a noção de probabilidade. Para o autor, o risco refere-se sempre a perigos calculados em função de possibilidades futuras.

Nasciutti (2020) ao estudar as perspectivas do mundo do trabalho após o confinamento social, sem data prevista de encerramento, afirma que o risco de perder o emprego tem gerado enorme prejuízo emocional na maioria dos trabalhadores. Muitas empresas estão sofrendo com a brusca interrupção de ingresso de receitas e com dificuldades financeiras, é possível que precisarão rever sua estrutura de cargos e decisões sobre demissões. Para Lhuilier (2020), é possível também correr o risco de se ver confrontado com uma "redobrada intensificação do trabalho, devido ao número de colegas ausentes e às tentações, já bem identificadas, de trabalhar mais para produzir mais, a fim de compensar o tempo perdido e as perdas associadas" (p. 93), que também podem provocar sofrimento.

O medo pode acarretar algumas outras consequências como a perda do prazer de trabalhar e o desaparecimento da confiança nos colegas (Dejours, 2006), que faz os trabalhadores sofrerem e muitas vezes, de maneira calada, pois as estratégias de defesa são difíceis de construir e manter. Para Giddens (2002), é considerado invisível "o que não pode ser posto em palavras" (p. 45) e em muitas situações, os trabalhadores sofrem em silêncio não conseguindo tornar visível o que estão sentindo.

\section{Considerações finais}

O desenvolvimento humano e social é um motor positivo para o desenvolvimento cultural, especialmente de valores de autoexpressão. Pelos dados mostrados trabalho, tais valores podem minimizar os riscos subjetivos de medo e insegurança, sempre sentimentos potencializadores de "lutos sociais". De um lado, a modernidade trouxe muitas promessas de emancipação e desenvolvimento. Porém, apenas alguns países conseguiram riscos "visíveis". Para os países periféricos, ou em desenvolvimento, pode-se dizer que há uma sobreposição dos riscos novos em relação aos antigos. Morre-se de fome, ao mesmo tempo em que cada vez mais pessoas sofrem dos distúrbios da alimentação. Ainda há pessoas que trabalham em condições de semiescravidão, mas há um forte movimento de automatização e robotização no mundo do trabalho.

Como observou Piketty (2020, p. 11): "toda sociedade humana precisa justificar suas desigualdades". Por isso, esse economista Francês tem apontado os indicadores econômicos e sociais da extrema desigualdade do mundo (Piketty, 2020; Piketty, 2013). Por mais que os riscos sejam distribuídos de forma global, os mais pobres, as mulheres, os negros e estrangeiros, as crianças e os idosos, entre outros grupos sociais, sofrem de forma mais forte as mazelas sociais e econômicas. Ou seja, há riscos, e a grande transformação tecnológica ainda não serviu para a superação dos riscos visíveis do passado para toda a sociedade global. Ainda há muito medo relacionado aos valores de sobrevivência, que, por outro lado, acabam trazendo à tona um certo apoio social para medidas políticas autoritárias, muitas vezes proponentes de soluções fáceis para os riscos materiais. Porém, a sobreposição de riscos novos e antigos acrescenta um outro elemento político muito significativo, pois desafia a implementação e gestão de políticas públicas que precisam estar voltadas para essa grande diversidade de situações.

Nesse sentido, também a análise da relação complementar de riscos e valores de autoexpressão/sobrevivência traz elementos políticos e democráticos, seja para a avaliação das políticas públicas e da gestão do Estado, como tem sido pesquisado no mundo (Roudijk, Donders, \& Stalmeier, 2019; Holum, 2018), como para a própria consolidação e sobrevivência da democracia (Levitsky, Ziblatt, 2018).

A complementaridade entre o luto e a autoexpressão é um sinal dos novos tempos, especialmente para sociedades com profundas 
desigualdades sociais, mas com crescimento e desenvolvimento tecnológico, como já foi apontado nos estudos sobre a dependência na América Latina desde os anos 60 do século XX (Cardoso, Faletto, 1984; Marini, 1992; Martins, 2011), que têm aproximado a pesquisa de três conceitos atuais: globalização, dependência e neoliberalismo (Martins, 2011).

A descoberta presente neste texto é que a autoexpressão não apenas pode ser um polo oposto de valores de sobrevivência, mas também pode estar relacionada, no mesmo polo, com o sentimento de luto. Dessa forma, a modernização dos últimos séculos trouxe alento para vastas camadas da população, mas também trouxe desesperança e medo. Por isso, além das organizações da sociedade civil, o poder público tem o desafio de gerenciar um contexto com profundas desigualdades, mas com grandes potenciais tecnológicos.

O medo já foi relacionado aos valores de sobrevivência, mas ele também pode estar, como sentimento de luto, relacionado aos valores de autoexpressão, numa espécie de cansaço que as pessoas estão tendo com esse apelo todo por felicidade, autoajuda, segurança e conforto.

\section{Referências}

Beck, U. (2010). Sociedade de risco: rumo a uma outra modernidade. São Paulo: Ed. 34.

Bendassolli, P., \& Borges-Andrade, J. E. (2011). Significado do trabalho nas indústrias criativas. Revista de Administração de Empresas, 51(2), 143159.

Cardoso, F. H., \& Faletto, E. (1984). Dependência e desenvolvimento na América Latina: ensaio de interpretação sociológica. Rio de Janeiro: Zahar Editores.

Cheung, S. Y. (2019). Lessons from an "old" second generation in the US: fresh evidence on assimilation theories. Ethnic and Racial Studies, 42(13), 2285-2290. doi: 10.1080/01419870.2019.1627477

Ciftci, S. (2018). Self-expression values, loyalty generation, and support for authoritarianism: evidence from the Arab world. Democratization, 25(7), 1132-1152. doi: $10.1080 / 13510347.2018 .1450388$

Dejours, C. (2006). O medo e a precarização do Trabalho. Sociedade do Risco. Entrevista conce-dida a IHU Online. Recuperado de http://www.ihuonline.unisinos.br/media/pdf /IHUOnlineEdicao181.pdf

Diener, E., Oishi, S. \& Lucas R. E. (2002). Subjetive well-being: The science of happiness and life satisfaction. In C. R. Snyder, \& S. Lopes (Eds.), Handbook of
Positive Psychology (pp. 187-194). New

York: Oxford University Press.

Freud, S. (2010). Luto e melancolia (Obras Completas de Sigmund Freud, vol.XII). São Paulo: Companhia das Letras (Original publicado em 1917).

Giddens, A. (1994). A vida em uma sociedade pós tradicional. In U. Beck, A. Giddens \& S. Lash (Orgs.), Modernização reflexiva: politica, tradição e estética na ordem social moderna. São Paulo: EdUnesp.

Giddens, A. (2002). Modernidade e identidade. Rio de Janeiro: Jorge Zahar.

Harari, Y. (2015). Homo Deus: uma breve história do amanhã. São Paulo: Companhia das Letras.

Han, B. (2019). Hiperculturalidade: cultura e globalização. Petrópolis, RJ: Vozes.

Han, B. (2015). A sociedade do cansaço. Petrópolis, RJ: Vozes.

Holum, M. L. (2018). How does competitive tendering and contracting affect satisfaction with mu-nicipal health and care services?. International Review of Administrative Sciences, 84(3) 520-538, doi: 10.1177\%2F0020852316630391

Inglehart, R. \& Welzel, C. (2009). Modernização, mudança cultural e democracia: a sequência do desenvolvimento humano. Brasília: Verbena. 
Inglehart, R., Haerpfer, C., Moreno, A., Welzel, C., Kizilova, K., Diez-Medrano J. ... B. Puranen (eds.). (2020). World Values Survey: All Rounds - Country-Pooled Datafile. Madrid, Spain \& Vienna, Austria: JD Systems Institute \& WVSA Secretariat. Recuperado de http://www.worldvaluessurvey.org/WVSD ocumentationWVL.jsp

Kapitány-Fövény, M., Richman, M. J., Demetrovics, Z., \& Sulyok, M. (2018). Do you let me symptomatize? The potential role of cultural val-ues in cross-national variability of mental disorders' prevalence. International Journal of Social Psychiatry, 64(8) 756-766, doi: 10.1177\%2F0020764018811361

Krys, K., Uchida, Y., Oishi, S., \& Diener, E. (2018): Open society fosters satisfaction: explanation to why individualism associates with country level measures of satisfaction. The Journal of Positive Psychology, 14(6), 768-778. doi: 10.1080/17439760.2018.1557243

Kübler-Ross, E. (2009). Sobre a morte e morrer (9 ed.). São Paulo: Martins Fontes.

Levitsky, S., \& Ziblatt, D. (2018). Como as democracias morrem. Rio de Janeiro: Zahar.

Lhuilier, D. (2020). E se essa crise mudasse radicalmente o mundo do trabalho. Caderno de Administração, 28, 89-94. doi: $10.4025 /$ cadadm.v28i0.53900

Lipovetsky, G., \& Serroy, J. (2011). Culturamundo: resposta a uma sociedade desorientada. São Paulo: Companhia das Letras.

Lourenço, N. (2019). Sociedade Global, Risco e Segurança. Revista de Estudos Constitucionais, Hermenêutica e Teoria do Direito (RECHTD) 11(2), 211-219. doi: 10.4013/rechtd.2019.112.05

Lövgren, J. (2018). Secular youth and religious practice: candle lighting in Norwegian folk high schools. British Journal of Religious Education, 40(2), 124-135. doi: $\underline{10.1080 / 01416200.2016 .1256268}$

Malvezzi, S. (2013). A gestão de pessoas no contexto da estrutura de redes: desafios para a sociedade, empresas e indivíduos. Perspectivas em Gestão \& Conhecimento, 3(3), 6-17.

Marini, R. M. (1992). América Latina: dependência e integração. São Paulo: Editora Brasil Urgente.

Martins, C. E. (2011). Globalização, dependência e neoliberalismo na América Latina. São Paulo: Boitempo.

Meireles, M. I. P. (2012). Entre a Submissão e a Revolta: Estudo Exploratório sobre o Medo Social do Desemprego nas Indústrias do Vestuário e Calçado (Dissertação de Mestrado). Departamento de Sociologia, Instituto Universitário de Lisboa, Portugal. Recuperado de http://hdl.handle.net/10071/6159

Nasciutti. J. C. R. (2020). Pandemia e perspectivas no mundo do trabalho. Caderno de Administração, 28(Ed. Esp.).

Noll, J., Rohmann A., \& Saraglou, V. (2018). Societal level of religiosity and religious identity expression in Europe. Journal of Cross-Cultural Psychology, 49(6), 959975, doi: $10.1177 \% 2 F 0022022117737302$

Piketty, T. (2020). Capital e ideologia. Rio de Janeiro: Intrínseca.

Piketty, T. (2013). Le capital au XXIe siècle. Paris: Seuil.

Pires, S. C., Pinto, A. L., \& Justo, A. M. (2021) Percepção de risco da violência urbana no estado do Espírito Santo. PSI UNISC, 5(1), 96-110. doi: 10.17058/psiunisc.v5i1.15335

Rawls, J. (2011). O Liberalismo político (Trad. Luís Carlos Borges). São Paulo: Editora WMF Martins Fontes.

Roudijk, B., Donders, A. R. T., \& Stalmeier, P. F. M. (2019). Cultural values: can they explain differences in health utilities between countries?. Medical Decision Making, 39(5), 605-616. doi: 10.1177\%2F0272989X19841587

Rudnev, M., \& Savelkaeva, A. (2018). Public support for the right to euthanasia: Impact of traditional religiosity and autonomy values across 37 nations. International Journal of Comparative Sociolo-gy, 59(4), 301-318. 
Salvagni, J. E., \& Veronese, M. V. (2017). Risco invisível: trabalho e subjetividade no setor elétrico. Psicol. soc. (Online), 29, e131134.

Schihalejev, O. Kuusisto, A. Vikdahl, L. \& Kallioniemi, A. (2019). Religion and children's percep-tions of bullying in multicultural schools in Estonia, Finland and Sweden. Journal of Beliefs \& Values, 41(3), 371-384. doi: 10.1080/13617672.2019.1686732

Slovic, P. (1987). Perception of Risk. Science, 236(4799), 280-285. doi: 10.1126/science.3563507

Spink, M. J. (2001). Trópicos do discurso sobre o risco: Risco- aventura como metáfora na modernidade tardia. Cadernos de Saúde Pública, 17, 1277-1311.

Teti, A., Abbott, P., \& Cavatorta, F. (2019). Beyond elections: perceptions of democracy in four Arab countries. Democratization, 26(4), 645-665, DOI: 10.1080/13510347.2019.1566903

Yoo, Y., Boland, R. J., Lyytinen, K. \& Majchrzak, A. (2012). Organizing for Innovation in the Digitized World. Organization Science, 23(5), 1398-1408. Recuperado de https://EconPapers.repec.org/RePEc:inm:or orsc:v:23:y:2012:i:5:p:1398-1408.
Van Horn. J. E., Taris, T. W., Schaufeli, W. B. \& Scheurs, P. J. G. (2004). The structure of occu-pational well-being: a study among Dutch teachers. Journal of Occupational and Organizational Psychology, 77, 365375.

Vial, G. (2019). Understanding digital transformation: A review and a research agenda. The Journal of Strategic Information Systems, 28(2), 118-144.

Zafar, R. (2019). Impact of income and education on socio-political values of women: an empirical study of Pakistani working women. Journal of Asian and African Studies, 54(5), 691-701. doi: 10.1177\%2F0021909619830718

Zizek, S. (2010). Viver no fim dos tempos. Lisboa: Relógio D'Água.

Zizek, S. (2015). Problemas no paraíso: do fim da história ao fim do capitalismo. Rio de Janeiro: Zahar.

Zizek, S. (2019). A coragem da desesperança: crônicas de um ano em que agimos perigosamente. Rio de Janeiro: Zahar.

Zhuravlev, D. (2017). Orthodox identity as traditionalism: construction of political meaning in the current public discourse of the Russian Orthodox Church. Russian Politics \& Law, 55(4-5), 354-375. 


\section{Dados sobre os autores:}

- Silvana Regina Ampessan Marcon: Possui Bacharelado em Psicologia pela Universidade de Caxias do Sul (1987), mestrado em Administração pela Universidade Federal do Rio Grande do Sul (1998) e doutorado em Psicologia (Linha Organizações, trabalho e aprendizagem) pela Universidade Federal de Santa Catarina (2008). Atualmente é proprietária - Decisão Recursos Humanos e professora doutora Titular da Universidade de Caxias do Sul. Tem experiência na área de Administração, com ênfase em Recursos Humanos, atuando principalmente nos seguintes temas: planejamento estratégico, psicologia, psicologia organizacional, saúde do trabalhador, administração em recursos humanos e gestão. Foi Chefe do Departamento de Psicologia da UCS de janeiro de 2003 a julho de 2007. Foi Diretora do Centro de Ciências Humanas da UCS de agosto de 2007 a julho de 2014. Professora em cursos de graduação e de especialização lato senso. Executou atividades no Setor de Avaliação Institucional ligado a Assessoria de Planejamento e Orçamento da UCS de 2014 até 2020. Realiza atividades no Centro de Inovação e de Tecnologias Educacionais da UCS, no núcleo de Gestão Universitária. Coordenadora do Programa de Pós-Graduação em Psicologia da UCS - Mestrado Profissional, a partir de julho de 2019. Membro da Associação Nacional de Pesquisa e Pós-Graduação em Psicologia e do quadro de docentes avaliadores do INEP - Basis.

- João Ignacio Pires Lucas: Graduado em Ciências Sociais (bacharelado, UFRGS, 1993), Especialista em Gestão e Liderança Universitária (UNIVAP, 2008), Mestre (1996) e Doutor em Ciência Política (2003) pela UFRGS. Atualmente é professor da área de humanidades da Universidade de Caxias do Sul e do Programa de Pós-Graduação em Psicologia / Mestrado Profissional da UCS. Foi assessor das Pró-Reitorias de Planejamento e Desenvolvimento Institucional e de Pós-Graduação em Pesquisa (período 2002-2006), sub-chefe do Departamento de Sociologia (mandato 2003-2005), chefe do Departamento de Sociologia (mandato 2005-2006) e Pró-Reitor de Planejamento e Desenvolvimento Institucional da UCS (período 2006-2009).Como pesquisador, tem tido uma atuação interdisciplinar, investigando e publicando sobre os riscos sociais e psicossociais do mundo do trabalho e das instituições. É membro do Instituto de Pesquisa Econômicas e Sociais da UCS - IPES - e dos Núcleos de Estudos em Direito e em Políticas Públicas e Sociais. direitos autorais para os artigos publicados são do autor, com direitos do periódico sobre a primeira publicação. Os autores somente poderão utilizar os mesmos resultados em outras publicações indicando claramente este periódico como o meio da publicação original. Em virtude de sermos um periódico de acesso aberto, permite-se o uso gratuito dos artigos em aplicações educacionais e científicas desde que citada a fonte conforme a licença CC-BY da Creative Commons. 